\title{
How can frameworks inform water quality objectives for the closure of the Ranger mine?
}

\author{
M Iles Energy Resources of Australia Ltd, Australia
}

\begin{abstract}
Planning for the closure of Energy Resources of Australia Ltd's (ERA) Ranger uranium mine requires an understanding of potential impacts to water quality in adjacent receiving waters. Potential mine impacts need to be evaluated in the context of the Commonwealth environmental requirements, which include possible incorporation of the site into Kakadu National Park; onsite (i.e. within the Ranger Project Area) impacts that are as low as reasonably achievable (ALARA); and protection of the people, ecosystem, and World Heritage and Ramsar wetland values of the surrounds. Adopting best practicable technology (BPT) is also required.

Water quality guideline values have been developed to support the management goal of achieving no change to biodiversity outside the Ranger Project Area. Guideline values to support the management goal of ensuring impacts onsite are ALARA, while still protecting the offsite values, have not been obtained. An agreed framework is needed to understand the changes that might occur at different concentrations of contaminants in the Ranger Project Area so that stakeholders can consider and assess whether such changes are ALARA and protective of the downstream values. The national water quality guidelines provide a framework for assessing remediation programs, while, under the environmental requirements, the closure of Ranger must be assessed using a BPT framework. Consideration of alternative management options, community, and environmental and cost aspects are common to both frameworks.

Additionally, ERA is working with consultants (BMT) and stakeholders to develop a risk-based vulnerability assessment framework to identify ecological and cultural endpoints for the environmental requirements, considering impact components such as duration, geographic extent and resilience, to determine how different concentrations of magnesium-potentially the most restrictive contaminant of concern-might affect these endpoints.

This paper describes an initial review of how these frameworks may be used to appraise the mine closure strategy's compliance with the environmental requirements. The review can inform discussions with stakeholders on a suitable approach for setting water quality objectives for closure.
\end{abstract}

Keywords: water quality objectives, guidelines, ALARA, BPT, vulnerability assessment, mine closure

\section{Introduction}

Energy Resources of Australia Ltd (ERA) operates the Ranger uranium mine in the Northern Territory of Australia. The Ranger Project Area, on the Traditional Estate of the Mirarr, is surrounded by both the World Heritage-listed Kakadu National Park and the Ramsar site, which is also within the Kakadu National Park (Figure 1).

The mine site is progressing towards closure, with decommissioning works to be completed by January 2026. High-level environmental requirements for the protection of people and the environment during and after mining at Ranger have been prescribed by the Australian Government (Commonwealth of Australia 1999). 


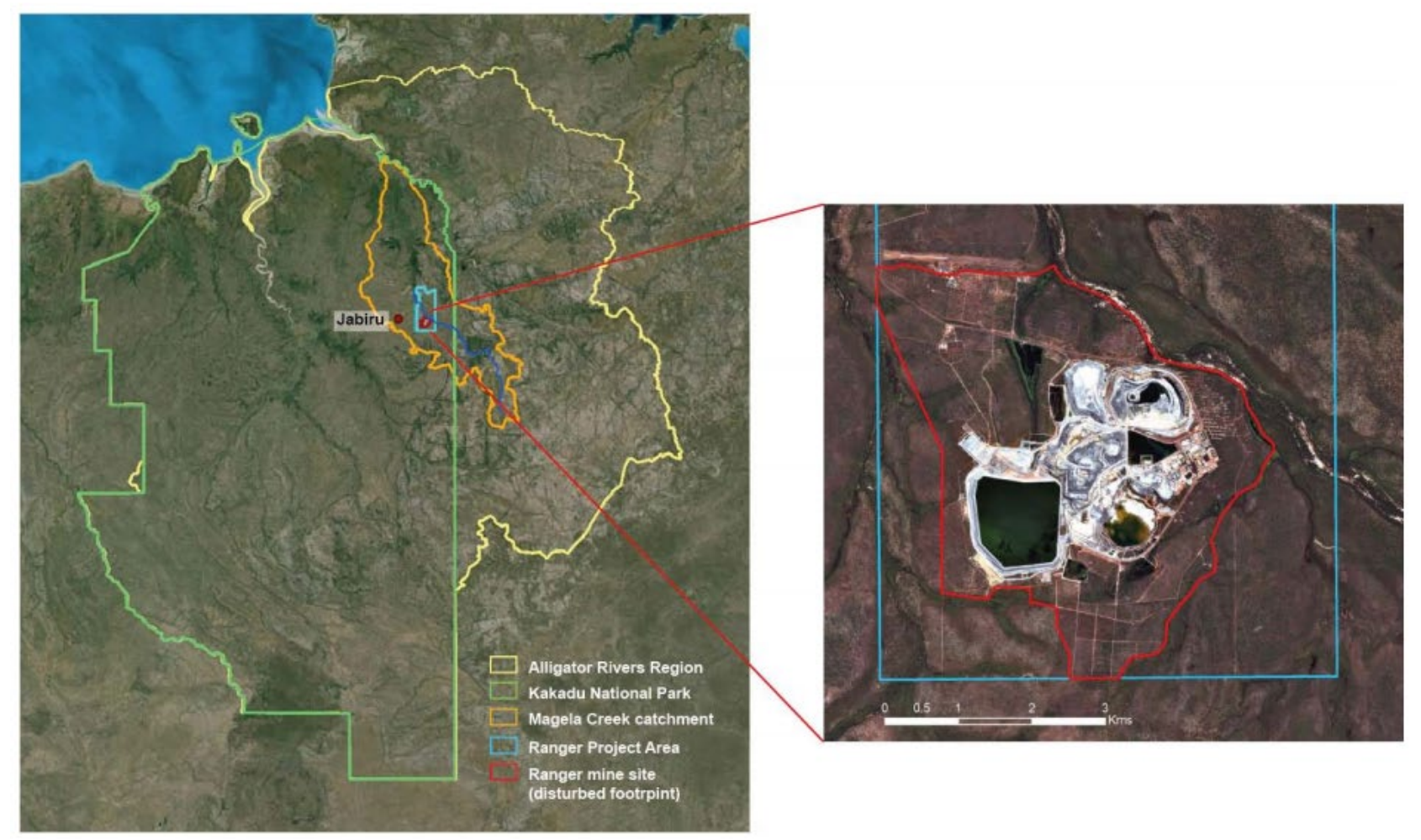

Figure 1 Ranger Project Area and mine site location

\subsection{Environmental requirements for closure}

The environmental requirements specify that the Ranger Project Area must be returned to a state in which it could be incorporated into Kakadu National Park, which is listed on the UNESCO World Heritage List for both its cultural and natural values (Environmental Requirement [ER] 2). Environmental requirements specific to the protection of water quality and decommissioning strategies specify:

- Waters leaving the Ranger Project Area do not compromise the achievement of the primary environmental objectives (ER 3.1) related to protection of the people, ecosystem (biodiversity and ecological processes), and World Heritage and Ramsar values of the surrounds (ER 1 and 2).

- Impacts on the Ranger Project Area are as low as reasonably achievable (ALARA) (ER 1.2e).

- The strategy adopted for closure of the mine uses best practicable technology (BPT) (ER12).

These environmental requirements provide high-level management goals for rehabilitation of the mine site. The Australian and New Zealand Guidelines for Fresh and Marine Water Quality (ANZG 2018) provides a sequential stepwise approach to protect the community values of waterways. The aim of the initial steps is to define management goals to protect the environmental values of different water types. In the context of the environmental requirements, management goals are focused on the protection of people, the ecosystem and the World Heritage and Ramsar wetland values.

\subsection{Closure objectives for water}

ERA is adopting default regional guidelines from ANZG (2018) and, where available, site-specific reference-based and biological effects-based guideline values for high-level species protection for aquatic ecosystems off the Ranger Project Area and values from the national drinking water and recreational guidelines at appropriate locations (still to be agreed with stakeholders).

The Supervising Scientist Branch in the Department of the Environment and Energy has developed site-specific guideline values based on methods used by the Australian and New Zealand Environment and 
Conservation Council and the Agriculture and Resource Management Council of Australia and New Zealand (ANZECC \& ARMCANZ 2000) and in ANZG (2018). These values provide water quality objectives for water leaving the mine site during operations; furthermore, they are suitable for meeting the closure objective for ecosystem protection off the Ranger Project Area.

ERA has engaged consultants to use numerical models to predict the concentration of a range of contaminants on, and downstream of, the mine site after closure. It is likely that concentrations higher than the Supervising Scientist Branch guideline values will occur in some locations on the disturbed mine footprint (i.e. within the Ranger Project Area; Figure 1). If concentrations do exceed the guideline value, this does not necessarily imply that impacts will occur. This situation is noted in ANZECC \& ARMCANZ (2000), which states that guideline values 'represent the concentration of chemical that would not cause a significant adverse effect on an ecosystem' and that exceedance implies the possibility, rather than the probability, of an adverse effect occurring.

ERA's draft closure objective for water quality in the Ranger Project Area (ERA 2018), reflecting ER 1.2e was stated as 'Surface water quality on the RPA [Ranger Project Area] meets the highest ecosystem protection level that is demonstrated to be reasonably achievable.' Stakeholder feedback recommended that quantifiable numeric values be derived to reflect ALARA values.

An agreed framework is needed in order to understand the impacts that predicted concentrations of contaminants will have on the environmental values and whether such impacts (i) will compromise the ability of the rehabilitated site to be incorporated into the Kakadu National Park and (ii) are ALARA.

ERA is considering several frameworks to assist this process and to derive numeric values to support the relevant values. This paper describes the initial stages of a review that describes how these frameworks might be used to appraise the mine closure strategy's compliance with the environmental requirements. The review can inform discussions with stakeholders on a suitable approach for setting water quality guideline values and objectives for closure.

\section{Assessment frameworks}

The assessment frameworks described in the following sections are taken from the environmental requirements and government publications on water management systems or have been developed by scientists to understand the response of key ecosystem components to chemical stressors. Stakeholders, including representatives of the Traditional Owners, have been involved to some extent in shaping some of these frameworks but not, thus far, in the application of them, as discussed in the following sections.

It is important to note that Traditional Owners have reported concerns about trying to integrate cultural values with the 'scientific, legal and technical domains of a process that will take place within a framework controlled by those from the dominant non-Indigenous culture' (Garde 2015).

All stakeholders will be involved in the decision-making regarding the process to adopt and the in the determination of water quality guideline values and objectives for closure. The process described below is one possible process, which can be used to inform discussions with stakeholders.

\subsection{Best practicable technology}

To comply with the environmental requirements, the closure of the Ranger mine must be implemented in accordance with BPT. The Supervising Scientist Branch interprets BPT as the technology that is consistent with achieving the primary environmental requirements and ranks highest when considering world's best practice, cost-effectiveness, proven effectiveness, Ranger's location, the age of equipment and social factors (Supervising Scientist 2001). The current definition of BPT according to the environmental requirements and an explanation of each BPT clause provided by the Supervising Scientist (2001) are presented in Table 1. 
Table 1 Explanation of environmental requirements for BPT (Supervising Scientist 2001, p. B-79)

Environmental requirement clause
"12.4 BPT is defined as:
That technology from time to time relevant to
the Ranger Project [Area] which produces the
maximum environmental benefit that can be
reasonably achieved having regard to all
relevant matters including:
(a) the environmental standards achieved by
uranium operations elsewhere in the world
with respect to
(i) level of effluent control achieved; and
(ii) the extent to which environmental
degradation is prevented;

(b) the level of environmental protection to be achieved by the application or adoption of the technology and the resources required to apply or adopt the technology so as to achieve the maximum environmental benefit from the available resources;

(c) evidence of detriment, or lack of detriment, to the environment;

(d) the physical location of the Ranger Project;

(e) the age of equipment and facilities in use on the Ranger Project and their relative effectiveness in reducing environmental pollution and degradation; and

(f) social factors including the views of the regional community and possible adverse effects of introducing alternative technology."

\section{Explanation}

"BPT

That technology that ranks highest when assessed against the factors below and is consistent with the Primary Environmental Objectives (Chapter 4).

\section{World's Best Practice}

Options must be compared with the environmental standards set by world's best practice in uranium mining and milling at the time they are to be implemented with respect to the level of effluent control achieved and the prevention of environmental degradation.

\section{Cost-effectiveness}

Options should be assessed with respect to both the level of environmental protection achieved, and the cost of implementation.

\section{Proven effectiveness}

Proposals for which there is practical evidence of their effectiveness should be favoured over proposals for which there is only experimental or theoretical evidence.

\section{Location}

The Ranger mine is located in the Wet/Dry tropics, on Aboriginal land surrounded by Kakadu National Park, remote from high population density cities. Hence the level of protection required for the environment and community is very high and the technology chosen should be designed accordingly.

Age of equipment

Technology in use should be reviewed periodically to determine whether or not recent advances have been made that would result in enhanced environmental protection.

Technology installed at Ranger in accordance with BPT should be reasonably allowed to fulfil its serviceable life with due consideration given to the advances in technology and the amount of serviceable life expended.

\section{Social factors}

The views of the regional community must be incorporated into BPT assessment. This includes where 


\begin{tabular}{ll}
\hline Environmental requirement clause & Explanation \\
\hline the introduction of new technology would improve the \\
level of environmental protection but may also have \\
negative social consequences. \\
Benefits in environmental effectiveness may not \\
necessarily result in greater social acceptability." \\
\hline
\end{tabular}

In considering the best procedure for ensuring that the BPT concept became a driver for identifying the best closure strategy at the Ranger mine, ERA expanded these categories to include cultural and heritage aspects and protection of the environment in the closure criteria themes of tailings, water, sediment, erosion, and ecosystem establishment (Johnston \& lles 2013). The new criteria remain consistent with the original six broad matters in the formal definition of BPT.

The BPT assessment process compares different management options and ranks them against each other based on scores for each of the BPT criteria. Knowledge of potential water quality (from modelling) and the relative changes under different options, including the potential impacts associated with the resulting water quality (from national and site-specific guidelines for different protection levels and the vulnerability assessment process), enable scoring of BPT criteria related to water quality. Likewise, information is presented to support the scoring of all other aspects against their relevant criteria. All scores are combined to form a single value, and the different options are ranked. The option with the best score is deemed BPT.

ERA proposes that the analyte concentration associated with the option that is considered BPT is the water quality that provides the lowest reasonably achievable impact. This aligns with the ALARA approach for radiation protection described by Oudiz et al. (1986), shown in Figure 2.

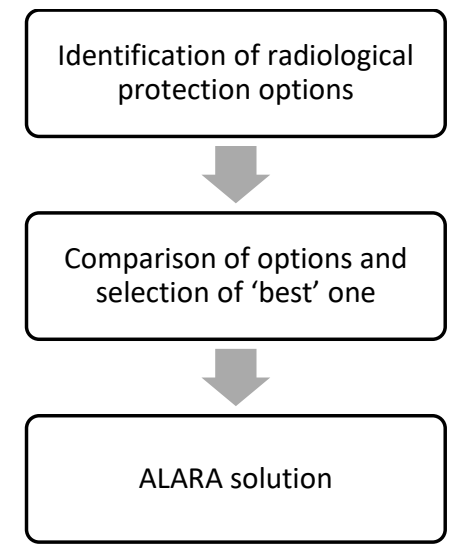

Figure 2 The main features of the ALARA procedure (Oudiz et al. 1986)

Garde (2015, p. 3) expressed the Traditional Owners' views regarding ALARA and BPT, stating that "the waters contained within all riparian corridors (i.e. rivers and billabongs), must be of a quality that is commensurate with non-affected riverine systems and health standards. The principle of 'as low as reasonably achievable' should not apply to these areas. Instead, the standard of rehabilitation must be as high as is technically possible and level of contamination must be as low as technically possible."

The national Water Quality Management Framework for assessing remediation programs (ANZG 2018) provides advice on setting spiritual and cultural guideline values and sits well with the BPT process. Consideration of alternative management options and the social, environmental and cost aspects are common to both frameworks.

\subsection{Water Quality Management Framework assessment for remediation programs}

ANZG (2018) states that 'after a decision has been made to remediate some aspect of a waterway, you can use the Water Quality Management Framework to assess the effectiveness of a remediation program'. 
The Water Quality Management Framework has been implemented by ERA to set water quality guideline values and objectives for the creeks running off the Ranger Project Area during operations. Much of the information used in that process is also applicable to the remediation context and can therefore assist stakeholders to reach agreement on environmental values and objectives for the Ranger Project Area after closure.

The closure context, community values, management goals and relevant indicators are understood through a large body of studies conducted over several decades, including those specific to closure knowledge needs (see ERA 2018, Chapter 7 and Supervising Scientist 2018). Additional work is in progress to further understand water quality closure risks and to inform a process for setting objectives for closure. Table 2 shows how some of the main studies have linked or are linking to the steps in the Water Quality Management Framework, with suggestions on how the steps may be used as part of the process to derive water quality objectives for closure.

This initial review is a preliminary assessment of how these processes can inform such decisions. Discussions with stakeholders individually and through various committees and responses to submitted reports and plans will provide feedback and information that can be used to refine or inform each step of the various processes, if adopted.

Table 2 Progress towards addressing the Water Quality Management Framework for mine closure

\section{Step and context}

1. Examine current understanding In order to inform decisions at subsequent steps, develop conceptual models of how the waterway systems work, the issues they face and how to manage them.

\section{Define community values and management goal}

Define community values and establish or refine more-specific management goals (including level of protection) for the relevant waterways at stakeholder involvement workshops.

\section{Define relevant indicators}

Select indicators for relevant pressures identified for the system, the associated stressors and the anticipated ecosystem receptors.

\section{Process to address for closure with respect to water quality}

Environmental risk assessments of the Ranger mine closure (Pollino et al. 2013; Pollino 2014; Bartolo et al. 2013).

Groundwater and surface water conceptual models developed (see references in ERA 2018).

Hydrological processes and ecosystem dynamics linked (BMT 2018).

Indigenous worldviews on the environment including waters is discussed in Garde (2015).

Environmental requirements provide the management goals for closure: (i) the Ranger Project Area can potentially be incorporated into Kakadu National Park, (ii) water leaving the site will not compromise the primary environmental objectives of ecosystem and human health and of Ramsar and World Heritage values, (iii) impacts on the Ranger Project Area are ALARA, and (iv) closure is implemented using BPT.

Garde (2015) describes the community's cultural expectations and expected uses of the rehabilitated mine.

A stakeholder workshop identified the water types in the project area and the environmental values for each water type based on the environmental requirements (BMT WBM 2017).

The Traditional Owners and the Supervising Scientist Branch have indicated that a goal of no change to biodiversity on the Ranger Project Area is preferred.

Endpoints and indicators for the protection of biodiversity (Supervising Scientist 2002) and that reflect the environmental values of water bodies both on and off the Ranger Project Area have been developed. These include indicators for health and cultural uses and the Ramsar and Kakadu National Park World 


\begin{tabular}{|c|c|}
\hline Step and context & Process to address for closure with respect to water quality \\
\hline \multirow{11}{*}{$\begin{array}{l}\text { 4. Determine water/sediment } \\
\text { quality guideline values } \\
\text { Determine the water/sediment } \\
\text { quality guideline values for each of } \\
\text { the relevant indicators required to } \\
\text { provide the desired level of } \\
\text { protection (if applicable) for the } \\
\text { management goals for relevant } \\
\text { waterways. }\end{array}$} & Heritage values (BMT WBM 2017). \\
\hline & $\begin{array}{l}\text { Bartolo et al. (2018) reviewed conceptual model endpoints and } \\
\text { important ecological processes. }\end{array}$ \\
\hline & $\begin{array}{l}\text { BMT (2018) defined the key ecological components underpinning } \\
\text { the environmental requirements of the Ranger Project Area and } \\
\text { surrounds and the interactions with underpinning processes. }\end{array}$ \\
\hline & Off the Ranger Project Area: \\
\hline & Guidelines have been developed and adopted as water quality \\
\hline & $\begin{array}{l}\text { objectives for the operational phase of mining (Turner et al. 2015). } \\
\text { Meeting these water quality objectives at the lease boundary } \\
\text { provides an assurance that no change will occur to the offsite } \\
\text { biodiversity. The same management goal, and hence the same } \\
\text { guidelines and objectives, will apply for off the Ranger Project Area } \\
\text { following closure. }\end{array}$ \\
\hline & On the Ranger Project Area: \\
\hline & $\begin{array}{l}\text { Guideline values based on the Supervising Scientist Branch's } \\
\text { ecotoxicity studies are available for species protection levels of } 95 \text {, } \\
90 \text { and } 85 \% \text {. Adoption of these guideline values was proposed by } \\
\text { ERA, but stakeholder feedback indicated that a process was } \\
\text { needed to determine whether these values were ALARA. To be } \\
\text { agreed with stakeholders, using an agreed process to determine } \\
\text { which water quality results in: }\end{array}$ \\
\hline & - Impacts that are ALARA (or vice versa). \\
\hline & - Protection of the Ramsar and World Heritage values. \\
\hline & $\begin{array}{l}\text { This paper suggests that the BPT process can support the first } \\
\text { point, and the vulnerability assessment process (Section } 2.3 \text { ) can } \\
\text { support the second. The decision on the extent to which this is } \\
\text { practical and desirable, and on which other assessments to } \\
\text { include, will be made with stakeholder involvement. }\end{array}$ \\
\hline \multirow{3}{*}{$\begin{array}{l}\text { 5. Define draft water/sediment } \\
\text { quality objectives } \\
\text { Use the guideline values or narrative } \\
\text { statements chosen for each selected } \\
\text { indicator as draft water/sediment } \\
\text { quality objectives to ensure the } \\
\text { protection of all identified } \\
\text { community values and their } \\
\text { management goals. }\end{array}$} & $\begin{array}{l}\text { The current water quality objectives (Turner et al. 2015) and } \\
\text { updates to same based on new science are applicable for the }\end{array}$ \\
\hline & management goals off the Ranger Project Area. \\
\hline & $\begin{array}{l}\text { See Sections, } 1.1,1.2 \text { and } 2.2 \text { regarding discussion of guidelines } \\
\text { and objectives for management goals on the Ranger Project Area. } \\
\text { The possible use of narrative statements as opposed to numeric } \\
\text { values is another area for further discussion. For example, the } \\
\text { process outlined in this paper could result in a statement about } \\
\text { implementation of the BPT option resulting in water quality that is } \\
\text { ALARA. }\end{array}$ \\
\hline $\begin{array}{l}\text { 6. Assess whether draft } \\
\text { water/sediment quality objectives } \\
\text { are met }\end{array}$ & \multirow{2}{*}{$\begin{array}{l}\text { The outputs of solute transport modelling of the closed mine } \\
\text { (in progress and future planned iterations) will determine whether } \\
\text { guideline values or objectives can be met under the proposed } \\
\text { closure strategy. }\end{array}$} \\
\hline $\begin{array}{l}\text { Use measurements from the } \\
\text { monitoring of each relevant } \\
\text { indicator to assess whether current } \\
\text { water/sediment quality meets the }\end{array}$ & \\
\hline
\end{tabular}




\begin{tabular}{|c|c|}
\hline Step and context & Process to address for closure with respect to water quality \\
\hline \multicolumn{2}{|l|}{$\begin{array}{l}\text { draft water/sediment quality } \\
\text { objectives. }\end{array}$} \\
\hline \multirow{3}{*}{$\begin{array}{l}\text { 7. Consider additional indicators or } \\
\text { refine the water/sediment quality } \\
\text { objectives } \\
\text { Assess the need to revise or add to } \\
\text { the lines of evidence or indicators } \\
\text { and the water/sediment quality } \\
\text { guideline values. }\end{array}$} & $\begin{array}{l}\text { Additional ecosystem component indicators have been developed } \\
\text { to represent endpoints for each of the primary environmental } \\
\text { objectives in the environmental requirements and cultural values }\end{array}$ \\
\hline & (BMT WBM 2017). \\
\hline & $\begin{array}{l}\text { A vulnerability assessment process is being developed in } \\
\text { consultation with stakeholders (Section 2.3). This involves } \\
\text { considering direct sensitivity to magnesium concentrations and } \\
\text { indirect sensitivity via other factors affecting vulnerability, such as } \\
\text { habitat, diet, reproduction and dispersion (BMT 2018). The process } \\
\text { could be extended to other stressors. }\end{array}$ \\
\hline $\begin{array}{l}\text { 8. Consider alternative management } \\
\text { strategies }\end{array}$ & $\begin{array}{l}\text { The overall closure strategy has been developed based on previous } \\
\text { BPT assessments (ERA 2018, Chapter 8). }\end{array}$ \\
\hline \multirow[t]{2}{*}{$\begin{array}{l}\text { Evaluate the effectiveness of current } \\
\text { management strategies to address } \\
\text { the identified water quality issues } \\
\text { and recommend possible } \\
\text { improvements. Improved or } \\
\text { alternative management strategies } \\
\text { are to be formulated, assessed and } \\
\text { prioritised. }\end{array}$} & $\begin{array}{l}\text { BPTs will be conducted to support plans for individual elements of } \\
\text { closure (e.g. Pit } 3 \text { closure, final landform, contaminated material } \\
\text { management, decommissioning of infrastructure and remediation } \\
\text { of wetlands and billabongs). Various options and mitigations will } \\
\text { be assessed against multiple criteria, including comparing potential } \\
\text { impacts associated with water quality with the goals for onsite and } \\
\text { offsite protection. }\end{array}$ \\
\hline & $\begin{array}{l}\text { A strategy that scores poorly on the social, environmental and/or } \\
\text { cost aspects is unlikely to be considered reasonable. The strategy } \\
\text { that scores highest on all aspects is likely to deliver impacts that } \\
\text { are ALARA. }\end{array}$ \\
\hline $\begin{array}{l}\text { 9. Assess whether water/sediment } \\
\text { quality objectives are achievable }\end{array}$ & $\begin{array}{l}\text { Predicted water quality post closure will be compared with the } \\
\text { agreed objectives for ecosystem protection onsite and offsite. }\end{array}$ \\
\hline \multicolumn{2}{|l|}{$\begin{array}{l}\text { Use information gained from Steps } 6 \\
\text { to } 8 \text { to assess whether the } \\
\text { water/sediment quality objectives } \\
\text { are achievable. }\end{array}$} \\
\hline \multirow{3}{*}{$\begin{array}{l}\text { 10. Implement agreed management } \\
\text { strategies } \\
\text { Document and implement agreed } \\
\text { management strategies, including, } \\
\text { in some cases, a suitable and agreed } \\
\text { adaptive management framework. }\end{array}$} & $\begin{array}{l}\text { Document in applications to stakeholders and regulators for } \\
\text { approval for key activities. Applications will include the results of } \\
\text { BPT assessments and the descriptions of mitigations and } \\
\text { management actions. }\end{array}$ \\
\hline & Stakeholder feedback will occur again at this stage. \\
\hline & $\begin{array}{l}\text { The Ranger mine closure plan will be updated annually on } \\
\text { progress. }\end{array}$ \\
\hline
\end{tabular}

\subsection{Vulnerability assessment}

ERA commissioned BMT to develop a framework to assist in understanding the potential impacts of contaminants on the environmental values associated with each of the primary environmental objectives stated in the environmental requirements. Of particular interest was the need to understand the environmental effects of magnesium at concentrations higher than the guideline value that was developed to provide the highest level of biodiversity protection. 
The initial phases of the project identified the relevant water types and the environmental values and indicators for waterways at, and adjacent to, the Ranger Project Area that specifically reflect community values and meet statutory requirements outlined in the environmental requirements (BMT WBM 2017).

The current stage of the program involves developing a framework to understand the vulnerability of the key species and functional groups identified as important ecological components underpinning the environmental values. The vulnerability assessment framework includes an appraisal of direct (i.e. toxicity) and indirect (i.e. food and habitat) sensitivity of the key species and groups to magnesium and their ability to avoid or recolonise after exposure.

The assessment is based on multiple lines of evidence and subject matter expert advice and participation in establishing the framework and undertaking the assessment. The results will identify important knowledge gaps and inform the ALARA and BPT assessments, thereby providing information with which to develop suitable water quality objectives for closure.

A separate paper in these proceedings and presentation by Darren Richardson (BMT) provides detail on the vulnerability assessment framework and the draft preliminary results.

\section{Conclusion}

The rehabilitation of the Ranger mine must (i) use BPT; (ii) ensure that the primary environmental objectives of protecting the health of people and the environment are met as well as the World Heritage and Ramsar values of Kakadu National Park off the Ranger Project Area; and (iii) result in impacts on the RPA that are as low as reasonably achievable and do not compromise the objective of incorporating the site into Kakadu National Park.

Water quality guideline values have been set for some of these goals, but an agreed process is needed to develop water quality guideline values and objectives that achieve the management goals for the Ranger Project Area after closure of the mine. The processes of BPT, ALARA and the vulnerability assessment being developed can align with steps in the Water Quality Management Framework set out in ANZG (2018).

This paper has discussed an initial review of the commonality of these processes and the progress already achieved in these processes. Stakeholder consultation will follow to discuss this review and how to improve the approach. Final design and eventual adoption of the framework will follow a consensus approach between Traditional Owner representatives, regulatory and supervisory agencies and ERA.

\section{Acknowledgement}

ERA acknowledges the Mirarr, the Traditional Owners of the lands that form the Ranger Project Area.

The author acknowledges the substantial body of research work and consultations conducted over several decades, in particular by the Supervising Scientist Branch and colleagues at ERA, which have led to the development of this framework, particularly with regard to informing the vulnerability assessment framework being developed by BMT.

\section{References}

ANZG 2018, Australian and New Zealand Guidelines for Fresh and Marine Water Quality, Water Quality Australia, viewed 2 February 2019, www.waterquality.gov.au/anz-guidelines

Australian and New Zealand Environment and Conservation Council \& Agriculture and Resource Management Council of Australia and New Zealand 2000, Australian and New Zealand Guidelines for Fresh and Marine Water Quality, Australian and New Zealand Environment and Conservation Council \& Agriculture and Resource Management Council of Australia and New Zealand, Canberra.

Bartolo, RE, Harford, AJ, Humphrey, CL, George, AK \& van Dam, RA 2018, 'Defining the importance of ecological processes for monitoring aquatic habitats for conservation and rehabilitation objectives at the Ranger uranium mine, Kakadu Region, Australia', Marine and Freshwater Research, vol. 69, pp. 1026-1046. 
Bartolo, R, Paulka S, van Dam, R, lles, S \& Harford, A 2013, Rehabilitation and Closure Ecological Risk Assessment for Ranger Uranium Mine: Documentation of Initial Problem Formulation Activities, Internal Report 624, October, Supervising Scientist, Darwin.

BMT 2018, Ranger Mine Closure Water Quality Framework Project: Phase 3 Preliminary (Working) Draft Report, BMT, Brisbane.

BMT WBM 2017, Ranger Mine Closure Water Quality Framework Project: Phase 2 Report, Reference: R.B22552.002.01. December BMT WBM, Brisbane.

Commonwealth of Australia 1999, Environmental Requirements of the Commonwealth of Australia for the Operation of Ranger Uranium Mine, viewed 2 February 2019, https://www.environment.gov.au/science/supervising-scientist/publications/ environmental-requirements-ranger-uranium-mine

Energy Resources of Australia Ltd 2018, Ranger Mine Closure Plan, Energy Resources of Australia Ltd, Darwin.

Garde, M 2015, Closure Criteria Development-Cultural, ERA Ranger Integrated Tailings, Water \& Closure, confidential report, Darwin.

Johnston, A \& Iles, M 2013, Integrated, Tailings, Water and Closure Prefeasibility Study: Analysis of Best Practicable Technology, Energy Resources Australia Ltd, Darwin.

Oudiz, A, Croft, J, Fleishman, AJ, Lochard, J, Lombard, J \& Webb, G 1986, What is ALARA?, Report CEPN No. 100, viewed 2 February, https://inis.iaea.org/collection/NCLCollectionStore/_Public/19/012/19012877.pdf?r=1\&r=1

Pollino, CA 2014, Ranger Rehabilitation and Closure Risk Assessment: Risk Screening, CSIRO Land and Water Flagship, Canberra.

Pollino, CA, Cuddy, SM \& Gallant, S 2013 Ranger Rehabilitation and Closure Risk Assessment: Problem Formulation, CSIRO Water for a Healthy Country Flagship, Canberra.

Supervising Scientist 2001, Annual Report 2000-2001, Department of the Environment and Heritage, Canberra.

Supervising Scientist 2002, Supervising Scientist Monitoring Program: Instigating an Environmental Monitoring Program to Protect Aquatic Ecosystems and Humans from Possible Mining Impacts in the Alligator Rivers Region, Supervising Scientist Division, Environment Australia, viewed 2 February 2019, http://www.environment.gov.au/system/files/resources/e40e696e-d97e4929-ba7c-126dbdbf032f/files/env-mon-prog-background.pdf

Supervising Scientist 2018, Annual Technical Report 2015-16, Commonwealth of Australia, Canberra.

Turner K, Tayler, K \& Tyrrell, JWR, 2015, Revised Ranger Mine Water Quality Objectives for Magela Creek and Gulungul Creek, Internal Report 638, Supervising Scientist, Darwin. 